\title{
2 »Geschichte des apostolischen Zeitalters« (A 102)
}

Die Besonderheiten dieses Manuskripts sind in der Einleitung unter Ziffer 5.2 dargestellt worden. Eine separate Inhaltsübersicht liegt dem Manuskript nicht bei. Die Überschriften sind dem laufenden Vorlesungstext in seiner jüngsten Fassung vom SS 1870 entnommen. Die von Overbeck vorgenommenen Unterstreichungen werden nicht reproduziert. Die Interpunktion wird vereinheitlicht.

Vorbemerkungen. $\$ 1$. Der Gegenstand und seine chronologischen Grenzen. p. $1-\$ 2$. Quellen dieser Geschichte. p. $7^{\mathrm{II}}-\$ 3$. Literatur. p. $37^{\mathrm{II}}$

Erster Abschnitt. Die jerusalemer Urgemeinde bis zum Auftreten des Paulus. - $\$ 4$. Die historischen Verhältnisse des palaestinensischen Judenthums. p. $46^{\mathrm{II}}-\S 5$. Chronologischer und örtlicher Ausgangspunkt der Geschichte des apostolischen Zeitalters. p. $61^{\text {Il }}-\$ 6$. Die Auferstehungsvisionen. p. $79^{\mathrm{II}}-\$ 7$. Die erste Messiaspredigt der Apostel Jesu. 15 p. $125-\$ 8$. Stephanus und die Hellenisten der Urgemeinde. Apg. c.6-8. p. $158-\$ 9$. Die Heidentaufe des Petrus. Apg. 10,1-11,18. p. $203-\$ 10$. Die Verfolgung der Urgemeinde unter Herodes Agrippa I. Apg. c.12. p. 212

Zweiter Abschnitt. Paulus. - $\$ 11$. Paulus vor seiner Bekehrung. 20 p. $225-\$ 12$. Die Christusvision des Paulus. p. $227-\$ 13$. Die Stellung des bekehrten Paulus zur Urgemeinde und sein erstes Auftreten als Apostel. Gal. 1,17-24. Apg. 9,19-30. p. $249-\$ 14$. Das paulinische Evangelium. - 1. Sein Verhältniss zur evangelischen Geschichte. - 2. Die Erlösung durch den Tod Jesu. - 3. Die Person des Erlösers. p. 250 - 25 $\$ 15$. Die apostolischen Reisen des Paulus bis zu seiner 1. Auseinandersetzung mit der Urgemeinde. (Die sog. 1. Missionsreise des Paulus.) p. $250-\$ 16$. Die Auseinandersetzung des Paulus mit der Urgemeinde und ihren Häuptern. (Das sogen. Apostelconcil.) Gal. 2,1-10. Apg. 15,1-33. p. $254-\$ 17$. Die letzten apostolischen Reisen des Paulus. 30 (Die sogen. 2. und 3. Missionsreise. Apg. 15,40-21,16.) p. $254-\$ 18$. Die Briefe des Paulus. p. 256 - $\$ 19$. Das Ende des Paulus. Apg. 21,17-28,31. p. $263-\$ 20$. Die letzten Schicksale der Urgemeinde bis zur Zerstörung von Jerusalem. p. 305-347. 